\title{
Effect of fluid resuscitation on acute lung injury in a rat model of sepsis
}

\author{
Erdogan $\mathrm{A}^{1}$, Erdogan $\mathrm{MA}^{2}$, Kara $\mathrm{AY}^{2}$, Bora $\mathrm{S}^{3}$, Yigitturk $\mathrm{G}^{4}$, Erbas $\mathrm{O}^{5}$ \\ Izmir Cigli Regional Training Hospital, Department of Emergency Medicine, Izmir, Turkey. \\ alpero86@gmail.com
}

\begin{abstract}
AIM: Sepsis is a systemic infection reaction and intravascular volume therapy plays a crucial role in it's treatment. Acute respiratory distress syndrome (ARDS) occurs in the lungs, the most affected organ. This study aimed to investigate the different effects of fluid therapy on ARDS caused by sepsis.

METHOD: To form a sepsis model, cecal ligation and puncture (CLP) procedure were performed on 44 adult rats. Divided into six groups; normal, CLP group, those treated with $40 \mathrm{ml} / \mathrm{kg} 0.9 \% \mathrm{NaCl}, 3 \% \mathrm{NaCl}$ (hypertonic saline), Ringer Lactate and Hydroxyethyl starch. After 24 hours treatments, histopathological examination of the lungs were done, and the plasma levels of CRP, TNF- $\alpha$ and IL- 6 and paO ${ }_{2}$ were measured.

RESULTS: The scores of all histological parameters of the group treated with hypertonic saline were significantly lower than of the other groups $(p<0.001)$. Likewise, according to the arterial blood gas results, $\mathrm{paO}_{2}$ was significantly higher $(\mathrm{p}<0.01)$ in the hypertonic saline group compared to the other groups, and $\mathrm{paCO}_{2}$ was significantly lower $(p<0.01)$. CRP, TNF- $\alpha$ and IL-6 levels of inflammatory markers were also significantly lower in hypertonic saline groups compared to other groups $(p<0.001)$.

CONCLUSIONS: Our study shows that treatment with hypertonic saline reduces the progression of ARDS in sepsis (Tab. 3, Fig. 4, Ref. 49). Text in PDF www.elis.sk KEY WORDS: ARDS, inflammation, lung injury, sepsis, volume replacement fluids.
\end{abstract}

\section{Introduction}

Sepsis, which is an erratic response of the host to infection, is a life threatening disease with a globally high mortality rate (1). Severe sepsis is a suspected or documented presence of infection with signs of systemic response which is accompanied by organ dysfunction (2). Mortality rates from serious sepsis exceed $25 \%$ to $45 \%$ in the case of septic shock, even with optimal treatment (2). Therefore, in order to perform the clinical management of sepsis in the best way, the resuscitation method should be selected as the most appropriate procedure.

Systemic inflammatory response syndrome, which usually begins with severe infection or acute injury, is a common problem in sepsis $(3,4)$. This syndrome has also caused multiple organ

\footnotetext{
${ }^{1}$ Izmir Cigli Regional Training Hospital, Department of Emergency Medicine, Izmir, Turkey, ${ }^{2}$ Izmir Katip Celebi University, Faculty of Medicine, Department of Physiology, Izmir, Turkey, ${ }^{3}$ Izmir Ataturk Training and Research Hospital, Department of Emergency Medicine, Izmir, Turkey, ${ }^{4}$ Mugla Sitki Kocman University, Faculty of Medicine, Department of Histology and Embryology, Mugla, Turkey,and ${ }^{5}$ Istanbul Bilim University, Faculty of Medicine, Department of Physiology, Istanbul, Turkey

Address for correspondence: M.A. Erdogan, Assoc Prof, Izmir Katip Celebi University, Faculty of Medicine, Department of Physiology, Izmir, Turkey. Phone: +90.543 .3818677$
}

dysfunction, including the lungs, liver, heart and kidneys $(3,5)$. The lungs are the most commonly affected organ in multiple organ dysfunction syndrome due to sepsis, and this syndrome takes the form of acute respiratory distress syndrome (ARDS) with lung injury $(6,7)$.

Although there are significant progresses in our experience about the pathophysiology of sepsis, treatments are still limited to aggressive fluid resuscitation, antibiotics, vasopressor administration and supportive care (8). Therefore, it is highlighted that there is a need to develop new therapeutic strategies for this syndrome. Intravenous (IV) fluid resuscitation is a critical component of the ideal treatment plan for serious sepsis patients (2). Consequently, the effect of various types of IV fluids has also been a popular subject of interest in sepsis studies and research (2). For all that it is still controversial about the use of optimum fluid replacement especially with regard to the kidney function. For example, though in European emergency clinics, gelatin and hydroxyethyl starch are generally used combination with crystalloids for fluid resuscitation, in North America crystalloids can be used frequently (9-12).

In sepsis induced ARDS and/or Acute Lung Injury (ALI), the lungs are the most severely inflamed and damaged areas $(13,14)$. The main cause of damage in ARDS is the destroying of the alveolar epithelium and pulmonary capillary endothelium by activated neutrophils, leukocytes, and macrophages, which form a large 
number of inflammatory mediators, interleukins (ILs), including tumor necrosis factor (TNF)- $\alpha$ (15). Thus, inflammatory processes must be evaluated regarding this information. Fluid resuscitation plays an essential role in septic tissue hypoperfusion therapy of hypovolemia (16). For this reason, this study was planned to research the effects of volume replacement by IV fluids on sepsis induced ARDS model in rats.

\section{Materials and methods}

\section{Animals}

In our study, 44 Sprague Dawley albino mature 200-220 g male rats were used. We received local Animal Ethics Committee's approval. And then all experimental procedures were performed according to the stated rules in the Guide for the Care and Use of Laboratory Animals adopted by the National Institutes of Health and ARRIVE guidelines. Animals were fed and kept in temperature - controlled steel cages $\left(21 \pm 2{ }^{\circ} \mathrm{C}\right)$ light-dark period for 12 hours.

\section{Experimental procedures}

In order to create a sepsis model, cecal ligation and puncture (CLP) procedure were performed on 44 rats as previously described $(16,17) .8$ rats were excluded from the study because they died. We randomly divided the rats into six groups. We designed the working groups as follows: Group 1: normal (non-operative and orally fed control, $n=6$ ); Group 2: CLP (untreated group, $n$ =6); Group 3: CLP and $40 \mathrm{ml} / \mathrm{kg} 0.9 \% \mathrm{NaCl}$ i.p $(\mathrm{n}=6)$, Group 4: CLP and $40 \mathrm{ml} / \mathrm{kg} 3 \% \mathrm{NaCl}$ i.p. $(\mathrm{n}=6)$, Group 5: CLP and $40 \mathrm{ml} / \mathrm{kg}$ Ringer Lactate i.p $(\mathrm{n}=6)$, Group 6: CLP and $40 \mathrm{ml} / \mathrm{kg}$ Hydroxyethyl starch (6 \% HES 130/0.4) i.p. We anesthetized the rats by intraperitoneally administering a combination of ketamine hydrochloride $(80 \mathrm{mg} / \mathrm{kg})$ and xylazine hydrochloride $(7 \mathrm{mg} / \mathrm{kg})$ according to the CLP procedure. Aseptically, the cecum was reached by applying $3 \mathrm{~cm}$ laparotomy from the midline of the rat. It was tightly tied at the base of the cecum with a 3.0 silk suture and pierced with a 22-gauge needle. A small amount of stool was then squeezed out of the puncture site. The cecum was placed back into the peritoneal cavity and the laparotomy incision was closed with 4-0 polyglactin sutures. Treatment was started in the first hour of the surgical procedure. All volume replacement therapies were given equally every 12 hours a day in two sections. All treatments were administered for 24 hours. When we ended the study, the rats were euthanized, biochemical analysis was performed from the blood sample taken by cardiac puncture, and histopathological examination was performed by pneumonectomy.

\section{Measurement of Arterial blood gas}

Carotid artery blood $(0.2 \mathrm{~mL})$ of rats was taken and $\mathrm{paO}_{2}$ and $\mathrm{paCO}_{2}$ levels were evaluated.

Measurement of plasma CRP, TNF- $\alpha$ and IL-6 levels

Biochemical analysis was performed from blood samples collected by cardiac puncture after the sacrifice procedure. Blood samples were centrifuged at $3000 \mathrm{rpm}$ for 10 minutes at room temperature and then stored at $-20{ }^{\circ} \mathrm{C}$. Commercially available enzyme-linked immunosorbent assay (ELISA) kits were used to evaluate CRP, TNF-a, and IL-6 levels. We identified all samples in duplicate according to the manufacturer's instructions.

\section{Histopathological examination of lung}

All rats were anesthetized by ketamine (40 mg/kg, Alfamine, Alfasan International B.V., The Netherlands) and xylazine (4 mg/kg, Alfazyne, Alfasan International B.V., The
Fig. 1. Lung Tissue. Hematoxylin and Eosin (H\&E) stain, X 20 magnification. a: Control group, normal alveolar and interstitial structure, b: CLP group, c: CLP and $0.9 \% \mathrm{NaCl}$ group, d: CLP and 3 \% NaCl group, e: CLP and Ringer Lactate group, f: CLP and HES group. 
Tab. 1. Changes in histopathological lung injury scores.

\begin{tabular}{lccccc}
\hline & $\mathrm{AC}$ & $\mathrm{H}$ & $\mathrm{AL}$ & $\mathrm{PE}$ & $\mathrm{TA}$ \\
\hline Control group & $0.3 \pm 0.2$ & $0.5 \pm 0.2$ & $0.6 \pm 0.3$ & $0.5 \pm 0.2$ & $0.3 \pm 0.2$ \\
CLP group & $4.3 \pm 0.4^{*}$ & $3.3 \pm 0.3^{*}$ & $4.3 \pm 0.4^{*}$ & $3.8 \pm 0.4^{*}$ & $4.3 \pm 0.4^{*}$ \\
CLP and 0.9\% NaCl group & $3.5 \pm 0.2^{\#}$ & $2.0 \pm 0.3^{\#}$ & $3.3 \pm 0.3^{\#}$ & $2.3 \pm 0.2^{\#}$ & $3.1 \pm 0.4^{\#}$ \\
CLP and 3\% NaCl group & $1.6 \pm 0.1^{\# \#}$ & $1.7 \pm 0.4^{\# \#}$ & $1.3 \pm 0.2^{\# \#}$ & $1.5 \pm 0.2^{\# \#}$ & $1.6 \pm 0.4^{\# \#}$ \\
CLP and Ringer Lactate group & $2.6 \pm 0.3^{\#}$ & $2.2 \pm 0.3^{\#}$ & $1.5 \pm 0.2^{\# \#}$ & $1.7 \pm 0.2^{\# \#}$ & $2.2 \pm 0.3^{\#}$ \\
CLP and HES group & $2.0 \pm 0.3^{\# \#}$ & $1.8 \pm 0.2^{\# \#}$ & $3.0 \pm 0.2^{\#}$ & $1.8 \pm 0.3^{\# \#}$ & $2.0 \pm 0.4^{\# \#}$ \\
\hline
\end{tabular}

" $\mathrm{p}<0.0001$, compared with Control group, ${ }^{\#} \mathrm{p}<0.05$, compared with CLP group, ${ }^{\#} \mathrm{p}<0.001$, compared with CLP group. Alveolar congestion (AC), hemorrhage $(\mathrm{H})$, infiltration or aggregation of leukocytes in air spaces/vessel walls

$(\mathrm{AL})$, perivascular/interstitial edema (PE), and thickness of the alveolar wall/hyaline membrane formation (TA)

Tab. 2. Arterial blood gas analysis.

\begin{tabular}{lcc}
\hline & $\mathrm{paO}_{2}(\mathrm{mmHg})$ & $\mathrm{paCO}_{2}(\mathrm{mmHg})$ \\
\hline Control group & $121 . \pm 51.7$ & $36.6 \pm 1.3$ \\
CLP group & $72.3 \pm 5.6^{*}$ & $55.3 \pm 4.2^{*}$ \\
CLP and 0.9\% NaCl group & $94.8 \pm 7.4^{\#}$ & $44.5 \pm 4.7^{\#}$ \\
CLP and 3\% NaCl group & $110 . \pm 64.7^{\# \#}$ & $39.5 \pm 3.3^{\#}$ \\
CLP and Ringer Lactate group & $95.6 \pm 5.4^{\#}$ & $45.1 \pm 1.3^{\#}$ \\
CLP and HES group, & $99.3 \pm 7.3^{\# \#}$ & $43.5 \pm 1.8^{\#}$ \\
\hline
\end{tabular}

${ }^{*} \mathrm{p}<0.001$, compared with Control group, ${ }^{\# \#} \mathrm{p}<0.01$, compared with CLP group, ${ }^{\#}$ $\mathrm{p}<0.05$, compared with CLP group

Netherlands) i.p. Lungs were removed for histological examination and fixed with formalin. During the examination, it was stained with hematoxylin/eosin. All stages were taken by the Olympus C-5050 digital camera mounted on the Olympus BX51 microscope. The basic histopathological lung injury score was calculated as used in previous publications (18). In a nutshell, histopathological lung damage was assessed by scoring alveolar congestion (AC), hemorrhage $(\mathrm{H})$, infiltration or aggregation of leukocytes in air spaces/vessel walls (AL), perivascular/interstitial edema (PE), and thickness of the alveolar wall/hyaline membrane formation (TA) (18). For all cases, the significance was graded on a scale of $1(0-25 \%), 2(25-50 \%), 3(50-75 \%)$, and 4 (75-100\%).

\section{Statistical analysis}

The data obtained from the subjects were compared with oneway analysis of variance (ANOVA). Post-hoc Tukey HSD test was used for comparison of the groups. Differences in control and treatment values were determined using Student's t-test. The limit of statistical significance was assigned to $\mathrm{p}<0.05$.

\section{Results}

\section{Hitopathological examination of lung}

Lung tissue histopathology changes are shown in Figure 1. Histopathological indicators of ARDS (hemorrhage, alveolar conges- tion, infiltration/ aggregation of leukocytes in air spaces-vessel walls, perivascular-interstitial edema, and thickness of the alveolar wall-hyaline membrane formation) were observed in the CLP group. In all groups, alveolar congestion was lowest in the group treated with $3 \% \mathrm{NaCl}(\mathrm{p}<0.001)$, whereas it was highest in the $0.9 \% \mathrm{NaCl}$ treated group $(\mathrm{p}<0.05)$. Hemorrhage and thickness of the alveolar wall-hyaline membrane formation scores were decreased in CLP $+3 \%$ $\mathrm{NaCl}$ and CLP + HES groups compared to $\mathrm{CLP}+0.9 \% \mathrm{NaCl}$ and CLP + Ringer Lactate groups $(\mathrm{p}<0.001)$. Infiltration-aggregation of leukocytes in air spaces-vessel walls score in the CLP $+3 \% \mathrm{NaCl}$ and CLP + Ringer Lactate groups were found to be lower than those in the CLP $+0.9 \% \mathrm{NaCl}$ and CLP + HES groups $(p<0.001)$. Perivascular/interstitial edema was also found to be decreased in CLP $+3 \% \mathrm{NaCl}, \mathrm{CLP}+$ Ringer Lactate and CLP + HES groups compared to the CLP group ( $p$ $<0.001)$. Overall, the score of all histological parameters about lung injury decreased substantially in the CLP $+3 \% \mathrm{NaCl}$ group relative to other groups (Tab. 1).

\section{Arterial blood gas analysis}

When we examine blood gasses, in all groups $\mathrm{PaO}_{2}$ were meaningfully lower than in the control group, however, $\mathrm{PaCO}_{2}$ was meaningfully higher $(\mathrm{p}<0.001)$. Likewise, $\mathrm{paO}_{2}$ in the CLP $+3 \% \mathrm{NaCl}$ group was significantly higher than in the other groups $(\mathrm{p}<0.01)$, moreover, $\mathrm{paCO}_{2}$ was significantly lower in this group $(\mathrm{p}<0.01)$ (Tab. 2).

\section{Plasma CRP, IL-6, TNF- $\alpha$ levels}

Serum CRP, IL- 6 and TNF- $\alpha$ levels of all groups are shown in Table 3. As shown in Figure 2, serum CRP levels were significantly higher in the CLP group compared to the control group $(\mathrm{p}<$ 0.0001 ). Among all groups, rats treated with $3 \% \mathrm{NaCl}$ had significantly lower CRP levels than other treatment groups $(p<0.001)$.

Plasma levels of TNF- $\alpha$ and IL-6 in all groups are shown in Figure 3 and 4 . The plasma levels of TNF- $\alpha$ and IL- 6 were significantly higher in the CLP-sepsis group compared with control group $(\mathrm{p}<0.0001)$. In the same pattern, there were significant inhibitions in TNF- $\alpha$ and IL- 6 levels in the CLP $+3 \% \mathrm{NaCl}$ group, compared to the other groups. TNF- $\alpha$ levels were significantly lower in the $\mathrm{CLP}+3 \% \mathrm{NaCl}$ and CLP + HES groups, while IL-6 levels were significantly lower in the CLP $+3 \% \mathrm{NaCl}$ and CLP $+0.9 \% \mathrm{NaCl}$ groups compared to the other treatment groups $(p<0.001)$.

Tab. 3. CRP, TNF- $\alpha$ and IL-6 levels.

\begin{tabular}{|c|c|c|c|c|c|c|}
\hline & $\begin{array}{l}\text { Control } \\
\text { group }\end{array}$ & CLP group & $\begin{array}{l}\text { CLP and } 0.9 \% \\
\mathrm{NaCl} \text { group, }\end{array}$ & $\begin{array}{l}\text { CLP and } 3 \% \\
\mathrm{NaCl} \text { group }\end{array}$ & $\begin{array}{l}\text { CLP and Ringer } \\
\text { Lactate group }\end{array}$ & $\begin{array}{l}\text { CLP and HES } \\
\text { group }\end{array}$ \\
\hline CRP (mg/dl) & $0.36 \pm 0.02$ & $0.79 \pm 0.03^{*}$ & $0.57 \pm 0.02^{\# \#}$ & $0.43 \pm 0.02^{\# \#}$ & $0.8 \pm 0.04$ & $0.63 \pm 0.03^{\#}$ \\
\hline TNF- $\alpha(\mathrm{pg} / \mathrm{ml})$ & $24.54 \pm 11.28$ & $212.38 \pm 34.65^{*}$ & $122.38 \pm 19.76^{\# \#}$ & $87.60 \pm 15.80^{\# \#}$ & $154.67 \pm 14.58$ & $107.99 \pm 37.52^{\#}$ \\
\hline IL-6 (pg/ml) & $40.53 \pm 7.56$ & $524.5 \pm 28.4^{*}$ & $228.4 \pm 37.8$ & $150.7 \pm 25.3^{\# \#}$ & $456.3 \pm 48.5$ & $234.0 \pm 38.4^{\#}$ \\
\hline
\end{tabular}

${ }^{*} \mathrm{p}<0.0001$, compared with Control group, ${ }^{\#} \mathrm{p}<0.05$, compared with CLP group, ${ }^{\#} \mathrm{p}<0.001$, compared with CLP group 


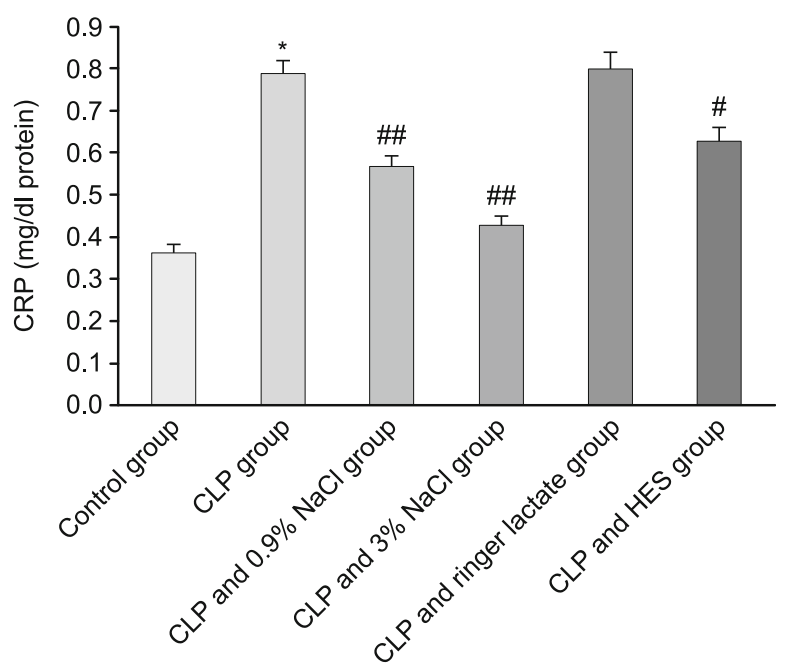

Fig. 2. The effect of volume replacement therapies on serum CRP levels. The results are expressed as mean \pm S.E.M. $* p<0.0001$, compared with Control group, \# $p<0.05$, compared with CLP group, \#\# $\mathrm{p}<0.001$, compared with CLP group.

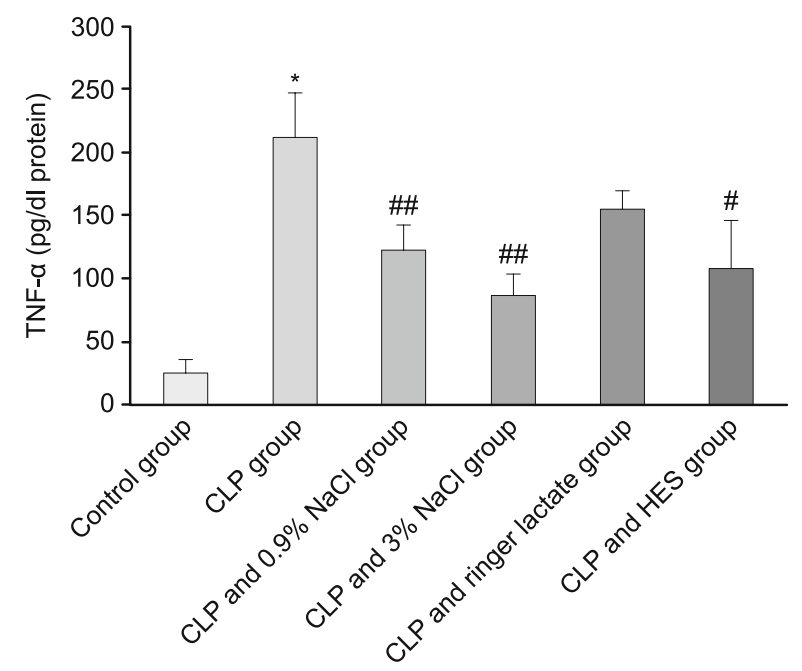

Fig. 3. The effect of volume replacement therapies on serum TNF- $\alpha$ levels. The results are expressed as mean \pm S.E.M. * $p<0.0001$, compared with Control group, \# $p<0.05$, compared with CLP group, \#\# $\mathrm{p}<\mathbf{0 . 0 0 1}$, compared with CLP group.

\section{Discussion}

Sepsis is a complicated clinical syndrome with a loud morbidity and mortality rate, with the development of progressive damage to multiple organ systems far from the site of infection (19). First and most severely affected organ is the lung. Therefore, the most common fatal complication of sepsis is acute respiratory distress syndrome (ARDS) $(20,21)$. As sepsis-induced ARDS is the first step in developing multi-organ dysfunction syndrome in critically ill patients, its prevention is an important therapeutic target.

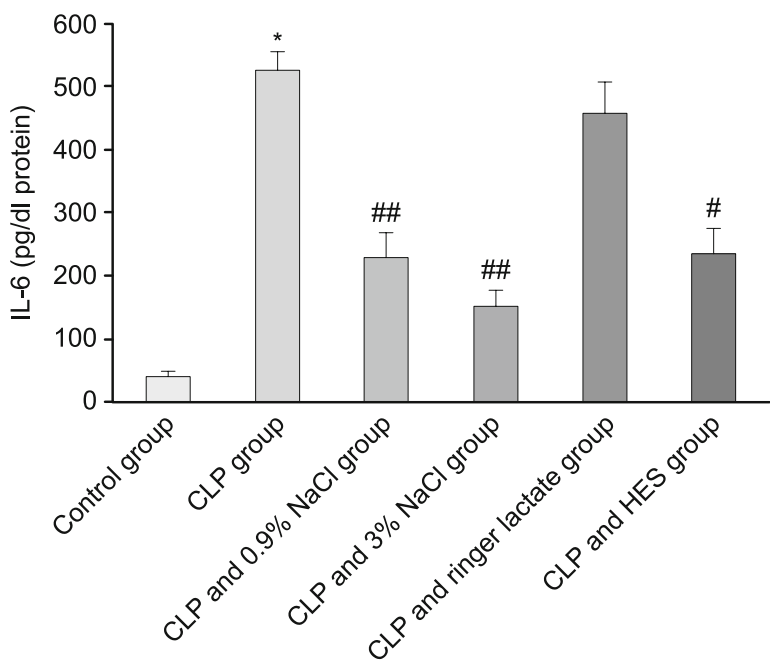

Fig. 4. The effect of volume replacement therapies on serum IL-6 levels. The results are expressed as mean \pm S.E.M. * $p<0.0001$, compared with Control group, \# $\mathbf{p}<0.05$, compared with CLP group, \#\# $\mathrm{p}<0.001$, compared with CLP group.

Mediators that cause inflammatory events in sepsis increase the microvascular permeability and cause leakage in capillaries, causing an increase in interstitial fluid, protein loss and tissue oedema. That is, sepsis is related to intravascular volume deficiency due to venous pooling, vasodilatation and endothelial barrier disruption $(22,23)$. Due to impaired albumin synthesis and increased loss from the transcapillary membrane, intravascular colloid osmotic pressure (COP) decreases, and the preservation of intravascular volume is impaired. Therefore, sepsis causes organ dysfunction due to insufficient tissue perfusion and oxygenation, resulting in arterial hypotension with reduced cardiac preload and output (24). In this clinical event, fluid resuscitation is the most important thing to restore and maintain the intravascular volume required for microcirculation and maintenance of tissue perfusion (25). As known, severe or extended hypotension is associated with bad clinical outcomes in patients with sepsis, while fast recovery of organ perfusion seems to be correlated with lower mortality rates (26). Nevertheless, there is no consensus on which type of fluid should be used as first-line therapy in resuscitation of septic shock patients.

Many studies have shown that fluid therapy is important in ARDS due to sepsis. However, positive fluid balance has also been shown to harm ARDS patients. Therefore, the key to treatment is to find the balance between pulmonary edema while achieving improvement in tissue perfusion (35). So, we planned this study to investigate which fluid is more effective in lung injury.

Acute respiratory distress syndrome includes microvascular lung damage, including accumulation of leukocyte in the tissue, pulmonary edema and inflammation (23). When we compared pulmonary edema, which suggests a protective effect on the lung, among the groups we used fluid therapy, we found that hypertonic saline was the best preventive measure. The edema interferes with lung function, changes the surfactant and deteriorates the barrier 


\section{0-286}

lesions of the alveolocapillary. Any effort to decrease edema could therefore have beneficial effects on respiratory function. Similar results have been found in other studies (27).

The inflammatory mechanism introduced during ARDS is characterized by the release of inflammatory mediators and the inflow of leukocytes in the pulmonary tissue (28). In our study, we also observed an increase in leukocyte infiltration in the untreated CLP group. We found that leukocyte infiltration in the lungs of groups treated with $0.9 \% \mathrm{NaCl}$ and HES could not be adequately prevented, but treatment with hypertonic saline significantly reduced the content of leukocytes. Supporting this, Oliveira et al suggests that the most interesting beneficial effect of hypertonic saline is the reduction of SIRS and attenuated MODS, especially in sepsis (29).

In consideration of perfusion, there was a study in the rat sepsis model caused by peritonitis (CASP) which determined that administration of the hydroxyethyl starch (HES) solutions provided no additional benefit on improvement of microcirculation in comparison to crystalloid solutions (30). Similarly, with regard to organ failure, it has been shown that albumin had no advantage over Ringer's Lactate (RL) on efficacy in reducing ventilator induced lung injury in an endotoxic rat model of sepsis (31). Nonetheless, there was also another study in rat cecal ligation and puncture (CLP) model of sepsis which showed that unbalanced crystalloid solution $(0.9 \% \mathrm{NaCl})$ was more effective on the development of acute kidney injury (AKI) and survival time when compared to a balanced crystalloid (Plasma-Lyte) (32). In another study in an endotoxic rat sepsis model it has been reported that synthetic colloid solution Hextend reduced mortality and lessened metabolic acidosis when compared to resuscitation with the saline or RL (33).

Unlike complicated findings from small-animal models, experiments in large animal models usually support the administration of colloid solutions in sepsis. Qui, et al. studied the effects of crystalloids $(0.9 \% \mathrm{NaCl}$ and $7.5 \% \mathrm{NaCl})$ or colloid (HES) solutions, on levels of vascular endothelial growth factor (VEGF), capillary permeability, and development of pulmonary edema in a sepsis dog model (2). Shown in studies, HES was more effective than crystalloid solutions in reducing tissue expression of VEGF, capillary permeability, and lung edema levels (34). However, there was another study performed in a sheep model of peritonitis induced sepsis which showed that even though the albumin and HES could improve the cardiac output, delivery of oxygen and reduce the blood lactate levels, there was no change in survival when compared with the administration of the crystalloid, RL (35).

In addition to the importance of clinical results associated with the amount and form of fluid resuscitation in septic care, the fundamental mechanisms to mediate these responses must also be examined. Recently, it has been shown that Nitric Oxide (NO) had a main role in sepsis pathophysiology. As it is known, the endothelium displays a vasodilatory response to fluid loading in order to tolerate increased blood flow and endothelial shear stress. In a hamster model of lipopolysaccharide (LPS)-induced sepsis, it has been demonstrated that enhancing or ameliorating NO bioavail- ability throughout sepsis may improve arteriole dilation, functional capillary density, and survival albeit reducing leukocyte endothelial interactions $(2,36)$. Vasopressin 1 receptor $(\mathrm{V} 1 \mathrm{R})$ is another player that has an important role in volume resuscitation therapy. It has been determined that in an endotoxic rat model, volume resuscitation can cause vasopressin release to enable the necessary V1R during the periods of low vasopressin secretion for an increased blood pressure in response to the fluids (37). The same pathway was also active and served a function after volume resuscitation in the CLP rat model of severe sepsis (38).

With a regard to inflammatory mechanisms, it has been shown that circulating TNF- $\alpha$ levels were substantially decreased in volume resuscitated animals compared to controls in the endotoxic rat sepsis model (2). The reduced TNF- $\alpha$ correlated with decreased total peripheral resistance (TPR), high cardiac beats, and higher survival rate (39). C-reactive protein (CRP) is an acutephase protein, which increase in blood rapidly in response to infection, trauma, ischemia, burns, and other inflammatory conditions (40). Because of these results, plasma CRP levels have been evaluated for a long time as an important biomarker for evaluating systemic inflammation (41). CRP levels have been shown to have prognostic/diagnostic significance in a great range of diseases, with the inclusion of sepsis, pneumonia, coronary artery disease, stroke and diabetes (42-44). Some studies indicate that CRP may be an indication of progressive organ damage (45-47). ARDS is an inflammatory process and many studies have centered on determining the function of inflammatory plasma mediators in this disease and how they correlate with phenotypes and clinical outcomes $(18,48,49)$. While literature studies associating CRP levels with prognoses in other diseases have been performed, there is little knowledge of the CRP function in ARDS and ALI patients. In our study, we also found a significant decrease in CRP, TNF- $\alpha$ and IL- 6 levels in the CLP $+3 \% \mathrm{NaCl}$ group when compared with the other groups. Therefore, this may be the first data about CRP and proinflammatory cytokine levels in sepsis-induced ARDS/ALI and since inflammatory processes have important role in sepsis, the effects of volume resuscitation on CRP levels and its underlying mechanisms need to be investigated in detail.

In our study, we showed that hypertonic saline was the most effective fluid for volume resuscitation. It reduced the lung injury parameters histologically, improved functional parameters in analysis of arterial blood gas and also had some anti-inflammatory effects with regard to CRP, TNF- $\alpha$ and IL-6 levels.

\section{Conclusion}

We demonstrate that hypertonic saline $3 \% \mathrm{NaCl}$-treatment significantly mitigates lung injury, with quantifiable suppression of injury parameters on lung histochemistry, increase in $\mathrm{paO}_{2}$ and reduction in $\mathrm{paCO}_{2}$ in the arterial blood gas analysis, and also decrease in CRP, TNF- $\alpha$ and IL- 6 levels. We also found that colloid solution HES can be more effective when compared with other crystalloids, $0.9 \% \mathrm{NaCl}$ and Ringer Lactate. Our findings replicate earlier published findings which demonstrated that hypertonic saline could ameliorate the ARDS/ALI in another rat model 
of sepsis and add to the body of evidence that hypertonic saline may serve as a first line therapy. Further studies are needed before these fluids can be suggested as a first line treatment and also for clarification of the underlying mechanisms of these different resuscitation fluids in sepsis-related ARDS/ALI.

\section{References}

1. Stevenson EK, Rubenstein AR, Radin GT, Wiener RS, Walkey AJ. Two decades of mortality trends among patients with severe sepsis: a comparative meta-analysis. Crit Care Med 2014; 42: 625-631.

2. Cornelius DC, McCalmon M, Tharp J, Puskarich M, Jones AE. Fluid Resuscitation in Animal Models of Sepsis: A Comprehensive Review of the Current State of Knowledge. Arch Emerg Med Crit Care 2016; 1 (1): 1002.

3. Singer M, Deutschman CS, Seymour CW et al. The third international consensus definitions for sepsis and septic shock (sepsis-3). JAMA 2016; 315: 801-810.

4. Blanco J, Muriel-Bombin A, Sagredo V et al. Incidence, organ dysfunction and mortality in severe sepsis: A Spanish multicentre study. Crit Care 2008; 12: R158.

5. Nesseler N, Launey Y, Aninat C, Morel F, Malledant Y, Seguin P. Clinical review: The liver in sepsis. Crit Care 2012; 16: 235.

6. Baue AE, Durham R, Faist E. Systemic inflammatory response syndrome (SIRS), multiple organ dysfunction syndrome (MODS), multiple organ failure (MOF): Are we winning the battle? Shock 1998; 10: 79-89.

7. Ware LB, Matthay MA. The acute respiratory distress syndrome. N Engl J Med 2000; 342: 1334-1349

8. Dellinger RP, Levy MM., Rhodes A. Surviving Sepsis Campaign: International guidelines for management of severe sepsis and septic shock, 2012. Intensive Care Medicine 2013; 39: 165-228.

9. Patel A, Laffan MA, Waheed U, Brett SJ. Randomised trials of human albumin for adults with sepsis: systematic review and meta-analysis with trial sequential analysis of all-cause mortality. BMJ 2014; 349: 4561 .

10. Farrugia A, Bansal M, Balboni S, Kimber MC, Martin GS, Cassar J. Choice of Fluids in Severe Septic Patients - A Cost-effectiveness Analysis Informed by Recent Clinical Trials. Rev Recent Clin Trials 2014; 9: $21-30$.

11. Perner A, Haase N, Wetterslev $\mathbf{J}$ et al. Comparing the effect of hydroxyethyl starch 130/0.4 with balanced crystalloid solution on mortality and kidney failure in patients with severe sepsis $(6 \mathrm{~S}-$ Scandinavian Starch for Severe Sepsis/Septic Shock trial): study protocol, design and rationale for a double-blinded, randomised clinical trial. Trials 2011; 12 (1): $1-9$.

12. Ertmer C, Rehberg S, Van Aken H, Westphal M. Relevance of nonalbumin colloids in intensive care medicine. Best Pract Res Clin Anaesthesiol 2009; 23: 193-212.

13. Compton CN, Franko AP, Murray MT, Diebel LN, Dulchavsky SA. Signaling of apoptotic lung injury by lipid hydroperoxides. J Trauma 1998; 44: 783-788.

14. Xiao X, Yang M, Sun D, Sun S. Curcumin protects against sepsisinduced acute lung injury in rats. Journal of Surgical Research 2012; 176 (1): e31-9.

15. Rivers EP, Jaehne AK, Eichhorn-Wharry L, Brown S, Amponsah D. Fluid therapy in septic shock. Curr Opin Crit Care 2010; 16: 297-308.
16. Erbas O, Taskiran D. Sepsis-induced changes in behavioral stereotypy in rats; involvement of tumor necrosis factor-alpha, oxidative stress, and dopamine turnover. J Surg Res, 2014; 186 (1): p. 262-8.

17. Bostanci H, Dikmen K, Comu FM, Arslan M, Kucuk A. Investigation of the effects of thymoquinone on erythrocyte deformability in sepsis treatment which created by cecal perforation in rat. Bratisl Med J 2018; 119 (3): 152-155.

18. Iraz M, Iraz M, Eşrefoglu M, Aydin MŞ. Protective effect of betaglucan on acute lung injury induced by lipopolysaccharide in rats. Turk J Med Sci 2015; 45 (2): 261-267.

19. Neviere RR, Ceepinskas G, Madorin WS et al. LPS pretreatment ameliorates peritonitis-induced myocardial inflammation and dysfunction: role of myocytes. Am J Physiol 1999; 277: H885.

20. Kollef MH, Schuster DP. The acute respiratory distress syndrome. N Engl J Med 1995; 332: 27-37.

21. Imm A, Carlson RW. Fluid resuscitation in circulatory shock. Crit Care Clin 1993; 9: 313-333.

22. Force AD, Ranieri VM, Rubenfeld GD, Thompson BT, Ferguson ND, Caldwell E. Acute respiratory distress syndrome. Jama 2012; 307 (23): 2526-33.

23. Marx G. Fluid therapy in sepsis with capillary leakage. Eur J Anaesthesiol 2003; 20 (6): 429-442.

24. Boldt J. Volume therapy in the intensive care patient - we are still confused, but. Intensive Care Med 2000; 26: 1181-1192.

25. Jones AE, Brown MD, Trzeciak S et al. Emergency Medicine Shock Research Network investigators. The effect of a quantitative resuscitation strategy on mortality in patients with sepsis: a meta-analysis. Crit Care Med 2008; 36: 2734-2739.

26. Petroni RC, Biselli PJ, de Lima TM et al. Hypertonic saline $(\mathrm{NaCl}$ $7.5 \%)$ reduces LPS-induced acute lung injury in rats. Inflammation 2015; 38 (6): 2026-35.

27. Koustova E, Stanton K, Gushchin V, Alam HB, Stegalkina S, Rhee PM. Effects of lactated ringer's solutions on human leukocytes. J Trauma 2002; 52: 872-878.

28. Oliveira RP, Velasco I, Soriano F, Friedman G. Clinical review. Hypertonic saline resuscitation in sepsis. Crit Care 2002; 6 (5): 418-23.

29. Wafa K, Herrmann A, Kuhnert T et al. Short time impact of different hydroxyethyl starch solutions on the mesenteric microcirculation in experimental sepsis in rats. Microvasc Res 2014; 95: 88-93.

30. Zhang H, Voglis S, Kim CH, Slutsky AS. Effects of albumin and Ringer's lactate on production of lung cytokines and hydrogen peroxide after resuscitated hemorrhage and endotoxemia in rats. Crit Care Med, 2003; 31: 1515-1522.

31. Zhou F, Peng ZY, Bishop JV et al. Effects of fluid resuscitation with $0.9 \%$ saline versus a balanced electrolyte solution on acute kidney injury in a rat model of sepsis. Crit Care Med, 2014; 42: 270-278.

32. Kellum JA. Fluid resuscitation and hyperchloremic acidosis in experimental sepsis: improved short-term survival and acid-base balance with Hextend compared with saline. Crit Care Med 2002; 30: 300-305.

33. Qiu YZ, Sun H, Li F. Effect of fluid resuscitation on capillary permeability and vascular endothelial growth factor in dogs with septic shock. Zhongguo Wei Zhong Bing Ji Jiu Yi Xue 2007; 19 (5): 270-273. 


\section{0-286}

34. Su F, Wang Z, Cai Y, Rogiers P, Vincent JL. Fluid resuscitation in severe sepsis and septic shock: albumin, hydroxyethyl starch, gelatin or ringer's lactate-does it really make a difference? Shock 2007; 27: 520-526.

35. Villela NR, dos Santos AO, de Miranda ML, Bouskela E. Fluid resuscitation therapy in endotoxemic hamsters improves survival and attenuates capillary perfusion deficits and inflammatory responses by a mechanism related to nitric oxide. J Transl Med 2014; 12: 232.

36. Batista MB, Bravin AC, Lopes LM et al. Pressor response to fluid resuscitation in endotoxic shock: involvement of vasopressin. Crit Care Med 2009; 37: 2968-2972.

37. Santiago MB, Vieira AA, Elias LL, Rodrigues JA, Giusti-Paiva A. Neurohypophyseal response to fluid resuscitation with hypertonic saline during septic shock in rats. Exp Physiol 2013; 98: 556-563.

38. Smith EF, Slivjak MJ, Egan JW et al. Fluid resuscitation improves survival of endotoxemic or septicemic rats: possible contribution of tumor necrosis factor. Pharmacology 1993; 46: 254-267.

39. Thijs LG, Hack CE. Time course of cytokine levels in sepsis. Intensive Care Med 1995; 21 (Suppl 2): S258-S263

40. Okamura JM, Miyagi JM, Terada K, Hokama Y. Potential clinical applications of $\mathrm{c}$ reactive protein. Journal of clinical laboratory analysis. 1990; 4 (3): 231-235.

41. Castelli GP, Pognani C, Cita M, Stuani A, Sgarbi L, Paladini R. Procalcitonin, C-reactive protein, white blood cells and SOFA score in ICU: diagnosis and monitoring of sepsis. Minerva anestesiologica 2006; $72(1 / 2): 69$.

42. Holm A, Pedersen SS, Nexoe J, Obel N, Nielsen LP, Koldkjaer O. Procalcitonin versus C-reactive protein for predicting pneumonia in adults with lower respiratory tract infection in primary care. Br J Gen Pract 2007; 57 (540): 555-560.
43. Ridker PM. Inflammatory biomarkers and risks of myocardial infarction, stroke, diabetes, and total mortality: implications for longevity. Nutr Rev 2007; 65 (suppl): S253-S259.

44. Pinilla JC, Hayes P, Laverty W, Arnold C, Laxdal V. The C-reactive protein to prealbumin ratio correlates with the severity of multiple organ dysfunction. Surgery 1998; 124 (4): 799-806.

45. Ikei S, Ogawa M, Yamaguchi Y. Blood concentrations of polymorphonuclear leukocyte elastase and interleukin- 6 are indicators for the occurrence of multiple organ failures at the early stage of acute pancreatitis. J Gastroenterol Hepatol 1998; 13: 1274-1283.

46. Rau B, Steinbach G, Baumgart K, Gansauge F, Grünert A, Beger HG. Serum amyloid A versus C-reactive protein in acute pancreatitis: clinical value of an alternative acute-phase reactant. Critical care medicine 2000; 28 (3): 736-742.

47. Liu KD, Glidden DV, Eisner MD et al. National Heart, Lung, and Blood Institute ARDS Network Clinical Trials Group. Predictive and pathogenetic value of plasma biomarkers for acute kidney injury in patients with acute lung injury. Critical care medicine 2007; 35 (12): 2755.

48. McClintock DE, Ware LB, Eisner MD, Wickersham N, Thompson BT, Matthay MA. Higher urine nitric oxide is associated with improved outcomes in patients with acute lung injury. American journal of respiratory and critical care medicine 2007; 175 (3): 256-262.

49. Parsons PE, Matthay MA, Ware LB, Eisner MD. Elevated plasma levels of soluble TNF receptors are associated with morbidity and mortality in patients with acute lung injury. Am J Physiol Lung Cell Mol Physiol 2005; 288 (3): L426-431.

Received October 6, 2020. Accepted October 26, 2020. 